\title{
Heat release rate in a reduced-scale model of a subway car on fire
}

\author{
Won-Hee Park ${ }^{1,2}$ \\ ${ }^{1}$ Transportation Environmental Research Team, Korea Railroad Research Institute, \#176, Choeldo bangmulgwan-ro, Uiwang-si, \\ Gyeonggi-do, 437-757 Korea \\ ${ }^{2}$ Railway System Engineering, Korea University of Science and Technology (UST), 217 Gajeong-ro Yuseong-gu, Daejeon, 305-350 Korea
}

\section{Email address:}

whpark@krri.re.kr

\section{To cite this article:}

Won-Hee Park. Heat Release Rate in a Reduced-Scale Model of a Subway Car on Fire. International Journal of Mechanical Engineering and Applications. Vol. 2, No. 5, 2014, pp. 64-69. doi: 10.11648/j.ijmea.20140205.12

\begin{abstract}
The heat release rate of a subway car on fire is measured for various positions of an ignition source and simulated materials differing in combustibility by using a reduced-scale model. Although the maximum HRR value is nearly independent of the position of the ignition source, the time required to reach this value varies greatly for different ignition positions. The open area of a subway car is a key factor that determines the maximum HRR value, although material combustibility also has an effect. Finally, the HRR curve is compared with that of a fire test in a real-scale subway car.
\end{abstract}

Keywords: Heat Release Rate (HRR), Subway Car, Reduced-Scale Model

\section{Introduction}

Various fire accidents including the Daegu subway fire in 2003 and the Austria mountain tunnel fire in 2001 have shown that fire accidents in underground tunnels are more dangerous than those above ground. Many studies have been conducted to anticipate and analyze tunnel fire phenomena. However, research on railcar fires as fire sources that determine the type and characteristics of a train tunnel fire remains insufficient. In particular, the characteristics of a passenger railcar fire vary depending on the structures and interior materials of the railcar. Previous studies on railcar fires include Amtrak's full-scale passenger railcar fire test [1] by the NBS (National Bureau of Standards) in 1984, the EUREKA 499 test [2] program in 1991, and the reduced-scale and full-scale fire research by Peacock et al. [3] in 1994. Ingason [4] has studied the change in the heat release rate (HRR) according to the conditions of ventilation by using a reduced-scale model railcar. Recently, full-scale fire tests for subway and inter-city railcars have been conducted [5] and analyzed [6]. Although full-scale experiments are ideal for collecting and analyzing accurate data, they incur considerable amounts of expense and effort. Therefore, reduced-scale tests have been actively conducted. Although these tests have limitations such as turbulence intensity, thermal inertia of materials, radiation heat effects, and fire propagation, they allow researchers to forecast quantitatively characteristics including the HRR and temperature more easily.

In this study, fire propagation phenomena were analyzed by measuring the HRR, mass loss rate, and temperature according to the location of ignition source and combustibility of interior materials by using a $1 / 10$-scale model of an actual subway car. In addition, the HRR was compared with that measured in an actual fire test conducted with a subway car.

\section{Tests Using Reduced-Scale Model}

\subsection{Froude Scaling}

In this research, Froude scaling [7] was used for the relation between a reduced-scale and an actual-scale subway car. The HRR measured in the reduced-scale model is converted using the following equation:

$$
Q_{R}=Q_{M}\left(L_{R} / L_{M}\right)^{5 / 2},
$$

where $\mathrm{Q}$ is the HRR, L is the character length, and the subscripts $\mathrm{R}$ and $\mathrm{M}$ denote real and model, respectively. Time as measured in the reduced-scale model is revised according to the following equation: 


$$
t_{R}=t_{M}\left(L_{R} / L_{M}\right)^{1 / 2},
$$

where $t$ is time. The actual total energy emitted is calculated with the following equation by using the energy emitted from the reduced-scale model:

$$
E_{R}=E_{M}\left(L_{R} / L_{M}\right)^{3}\left(\Delta H_{c, M} / \Delta H_{c, R}\right)
$$

where $\mathrm{E}$ is the total heat content and $\Delta \mathrm{Hc}$ is the heat of combustion.

\subsection{Reduced-Scale Subway Car}

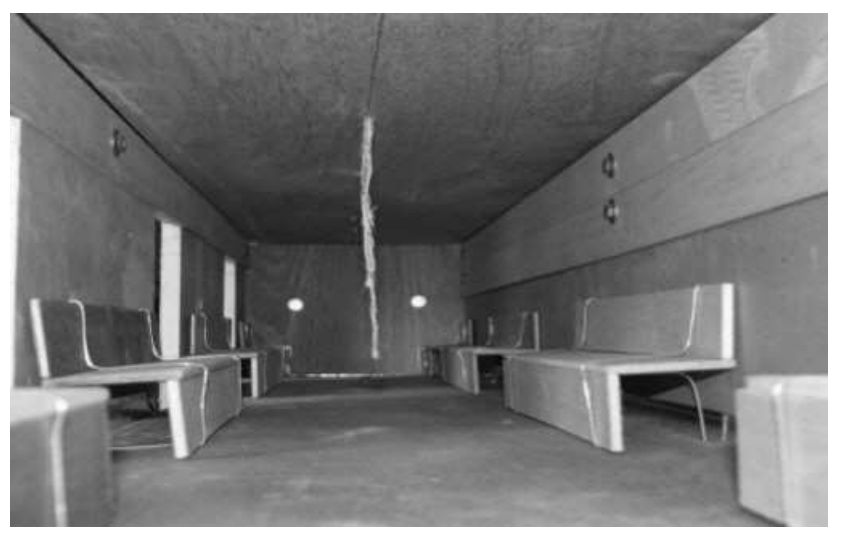

(a) Inside of the reduced-scale model

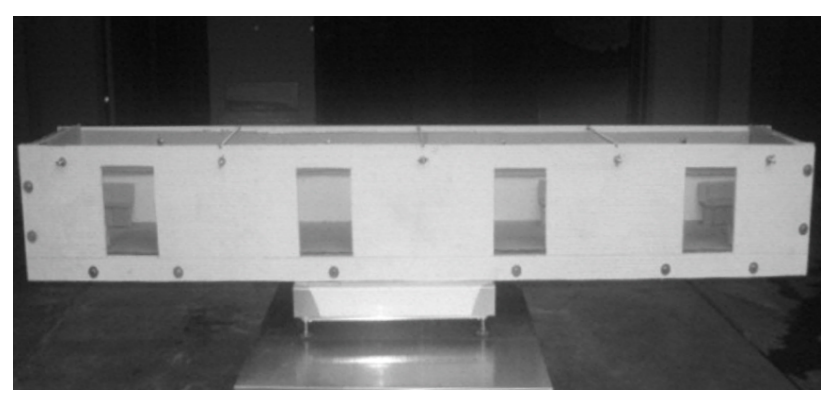

(b) Outside of the reduced-scale model.

Figure 1. Reduced-scale model.

The model in this study was a 1/10-scale model of an actual subway car operated in Seoul (Figure 1). The dimensions of the reduced-scale model are $1.9 \mathrm{~m}$ in length, $0.29 \mathrm{~m}$ in width, and $0.235 \mathrm{~m}$ in height. The length of the actual train is $19.7 \mathrm{~m}$. LR/LM, the reciprocal of the scale ratio in eqs. (1)-(3), is 10.37 . Generally, when a fire breaks out in a subway car and the train is stopped at the platform, all four doors at the sidewall near the platform will open for passenger evacuation. Therefore, in the reduced-scale model, all four doors at the sidewall were open. Each door was 0.13 $\mathrm{m}$ in width, $0.185 \mathrm{~m}$ in height, and $0.02405 \mathrm{~m} 2$ in area. The total ventilation area when the four doors were open was $0.0962 \mathrm{~m} 2$. The plaster board, which was used as the structural material for the reduced-scale car, weighed $28 \mathrm{~kg}$ and had a density of $860 \mathrm{~kg} / \mathrm{m} 3$, a thickness of $0.016 \mathrm{~m}$, and a thermal conductivity of $0.069 \mathrm{~W} / \mathrm{mK}$. The interior materials were manufactured based on the size of the ceiling, floor, and ends of an actual subway car, and then attached to the plaster boards. As shown in Figure 1(a), interior materials with dimensions of $0.045 \mathrm{~m} \times 1.9 \mathrm{~m}$ and $0.09 \mathrm{~m} \times 1.9 \mathrm{~m}$ were attached to the sidewalls with and without open doors, respectively. The ceiling and floor were completely covered by interior materials. At both ends, small seats were installed as in an actual subway car. Long seats were installed at the sidewall sections between doors. For the long seat, the size of the seating area was $0.055 \mathrm{~m} \times 0.312 \mathrm{~m}$; the back of the seat and support measured $0.04 \mathrm{~m} \times 0.312 \mathrm{~m}$. For the small seat, the size of the seating area was $0.055 \mathrm{~m} \times 0.134 \mathrm{~m}$, and that of the back of the seat and support measured $0.04 \mathrm{~m} \times 0.134$ $\mathrm{m}$. All interior materials were attached using bolts without adhesive bond. The total surface area of the interior materials used for the ceiling and floor was $0.551 \mathrm{~m} 2$, that for both ends was $0.06815 \mathrm{~m} 2$, and that for the sidewalls with or without open doors was 0.0855 or $0.171 \mathrm{~m} 2$, respectively. The total cross-sectional areas of the four small seats and six large seats were $0.07236 \mathrm{~m} 2$ and $0.25434 \mathrm{~m} 2$, respectively.

\subsection{Materials of Model Car}

Corrugated cardboard $7 \mathrm{~mm}$ thick and plywood 3 or $5 \mathrm{~mm}$ thick were used as the interior materials. To determine the combustibility of each interior material, the combustion behaviors of the 7-mm corrugated cardboard and the 3- or 5-mm thick plywood under incident heat fluxes of 10, 20, and $30 \mathrm{~kW} / \mathrm{m} 2$ were measured using a ISO5660-compliant cone calorimeter [8]. The oxygen consumption calorimeters employed in this study, such as the cone calorimeter and the large-scale calorimeter of ISO9705 [9], were used to measure the HRR from the reduced-scale model. The HRR is calculated by measuring the amount of emitted flow and concentration of oxygen in the combustion gas to quantify the consumption of oxygen by combustion. The HRR, or Q, from the fire is calculated as [10],

$$
Q=E \cdot \dot{m} \cdot \frac{M_{\mathrm{O}_{2}}}{M_{\text {air }}}\left(1-X_{\mathrm{H}_{2} \mathrm{O}}^{0}\right) / \frac{\alpha-1}{X_{\mathrm{O}_{2}}^{0}}+\frac{1-X_{\mathrm{O}_{2}} / 1-X_{\mathrm{CO}_{2}}}{X_{\mathrm{O}_{2}}^{0}-X_{\mathrm{O}_{2}}\left(1-X_{\mathrm{CO}_{2}}\right) / X_{\mathrm{CO}_{2}}} .
$$

Here, $\mathrm{E}[\mathrm{kJ} / \mathrm{kg}]$ is the amount of energy per consumed unit of oxygen, $\dot{m}[\mathrm{~kg} / \mathrm{s}]$ is the mass flow in the exhaust duct, $\mathrm{M}$ is the molecular weight, $\mathrm{X}$ is the mole fraction, and $\alpha$ is the ratio between the number of moles of combustion products including nitrogen and the number of moles of reactants including nitrogen. The superscript 0 denotes the value in ambient air.

Test results for the cardboard and plywood specimens are shown in Table 1. The combustion behavior under a certain incident heat flux was measured three times under each heat flux; the averages are summarized in Table 1. Only the corrugated cardboard was ignited under a heat flux of 10 $\mathrm{kW} / \mathrm{m} 2$; in contrast, neither plywood was ignited. A higher incident heat flux caused specimens to ignite faster and show higher maximum HRR values. The effective heat of combustion for the cardboard and the plywood of two thicknesses were 8.01, 7.90, and $6.56 \mathrm{~kJ} / \mathrm{g}$, respectively. The cardboard gave the largest heat of combustion among the 
tested specimens in a fire.

Table 1. Cone calorimeter results for materials of the model car

\begin{tabular}{|c|c|c|c|c|c|c|c|c|c|}
\hline \multirow{3}{*}{$\begin{array}{l}\text { Thickness (mm) } \\
\text { Heat flux (kW/m2) }\end{array}$} & \multirow{2}{*}{\multicolumn{3}{|c|}{$\begin{array}{l}\text { Cardboard } \\
7 \text { (case A) }\end{array}$}} & \multicolumn{6}{|c|}{ Plywood } \\
\hline & & & & \multicolumn{3}{|c|}{3 (case B) } & \multicolumn{3}{|c|}{5 (case C) } \\
\hline & 10 & 20 & 30 & 10 & 20 & 30 & 10 & 20 & 30 \\
\hline Max. HRR (kW/m2) & 106 & 110 & 144 & - & 242 & 274 & - & 175 & 190 \\
\hline Time to ignition (s) & 253 & 36 & 13 & - & 112 & 39 & - & 188 & 61 \\
\hline Effective heat of combustion $(\mathrm{kJ} / \mathrm{g})$ & \multicolumn{3}{|l|}{8.01} & \multicolumn{3}{|c|}{7.90} & \multicolumn{3}{|c|}{6.56} \\
\hline
\end{tabular}

\subsection{Ignition Source}

The fire source was placed at 1 of the 3 positions shown in Figure 2. The first location (case 1) was between the left end of the subway car and the seat, and the second (case 2) was between the second seat on the left and the second door on the left. The third location (case 3) was at the center of the subway car. The test conditions are summarized in Table 2 . The fire source in this test was a square pool pan $(0.04 \mathrm{~m} \times$ $0.04 \mathrm{~m}) 0.02 \mathrm{~m}$ in height with $\mathrm{n}$-heptane as the fuel. The HRR of the fire source used for the reduced-scale model was measured 6 times by using a cone calorimeter. The average HRR during $300 \mathrm{~s}$ was $1 \mathrm{~kW}$, and the HRR of the full-scale model as calculated by eq. (1) was $350 \mathrm{~kW}$.
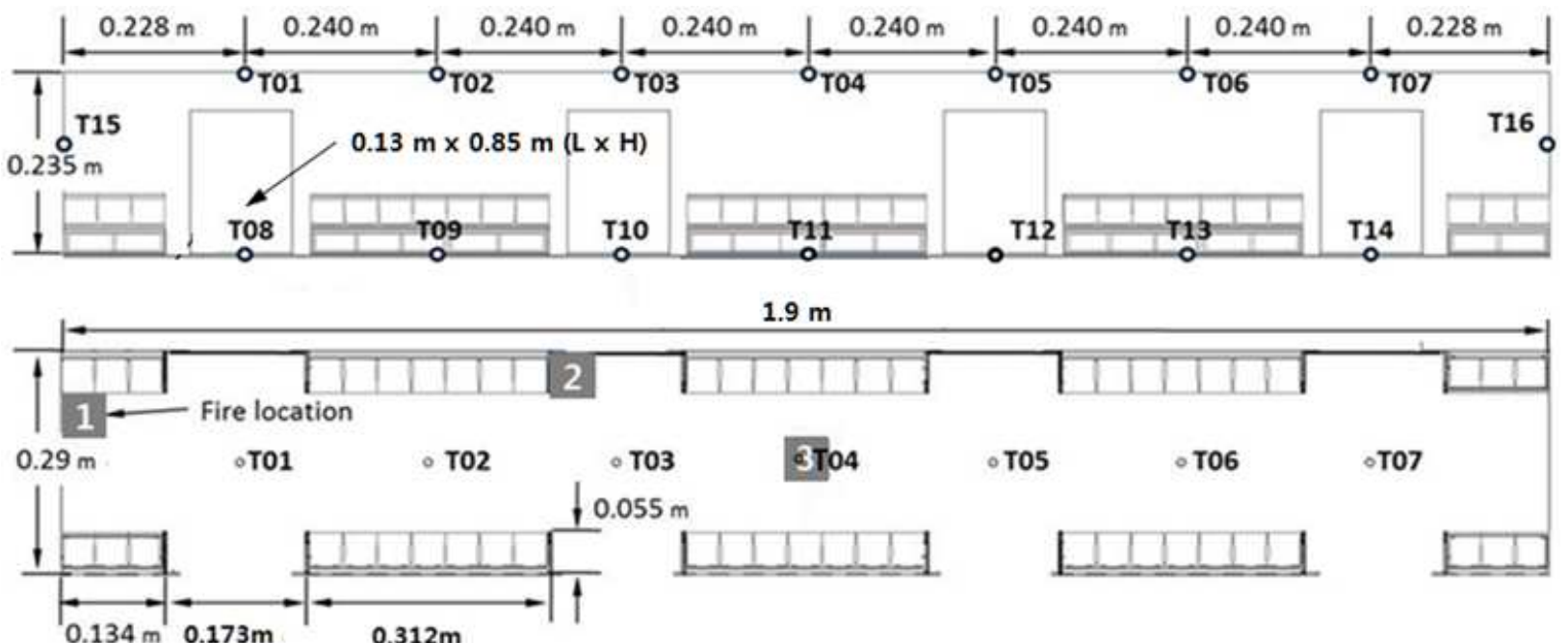

Figure 2. Positions of ignition sources and thermocouples.

Table 2. Test conditions for various materials and fire source locations

\begin{tabular}{llll}
\hline & Corrugated cardboard & Plywood (3 mm) & Plywood (5 mm) \\
\hline at 1 in Fig. 2 & case A1 & case B1 & case C1 \\
at 2 in Fig. 2 & case A2 & case B2 & case C2 \\
at 3 in Fig. 2 & case A3 & case B3 & case C3 \\
\hline
\end{tabular}

Table 3. Maximum HRR and its time of occurrence for all cases in the reduced-scale model

\begin{tabular}{|c|c|c|c|c|c|c|c|c|c|}
\hline \multirow{2}{*}{ Case } & \multicolumn{3}{|l|}{$\mathbf{A}$} & \multicolumn{3}{|l|}{ B } & \multicolumn{3}{|l|}{$\mathbf{C}$} \\
\hline & 1 & 2 & 3 & 1 & 2 & $3 *$ & 1 & 2 & $3^{*}$ \\
\hline Peak HRR & 71.43 & 83.78 & 82.37 & 49.82 & 51.32 & 9.06 & 70.81 & 64.30 & 12.43 \\
\hline Time to reach peak HRR & 123 & 204 & 258 & 426 & 564 & 351 & 501 & 1023 & 351 \\
\hline Ratio of max. peak HRR for each case to peak HRR & 0.85 & 1 & 0.98 & 0.97 & 1 & $0.19 *$ & 1 & 0.91 & 0.18 \\
\hline
\end{tabular}

*Fire spread out only near the source 


\subsection{Measurements in Model}

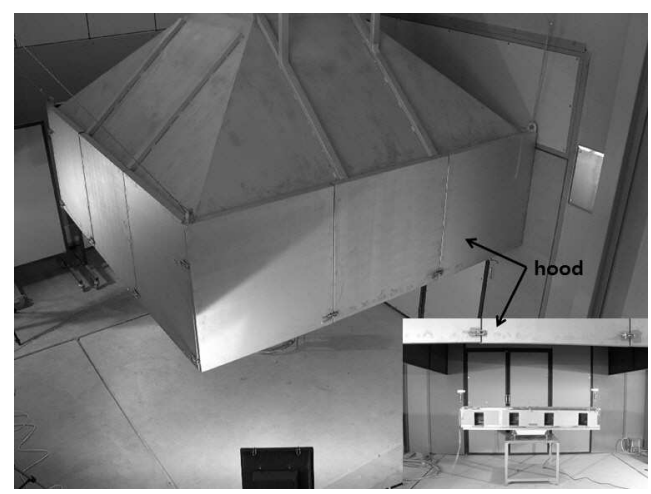

Figure 3. Hood of the fire test room and the model.

To measure the HRR of the reduced-scale model subway car on fire, the model was placed under the exhaust hood in

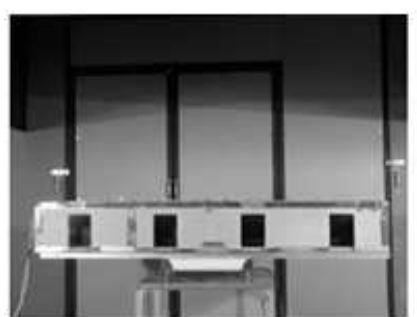

Os

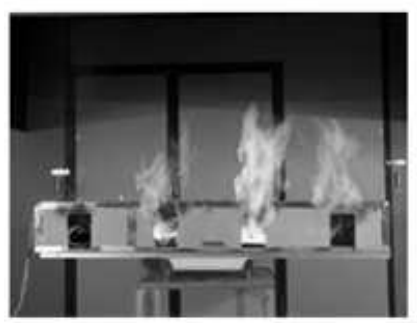

$440 s$

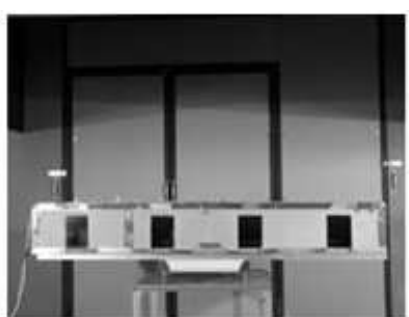

$100 \mathrm{~s}$

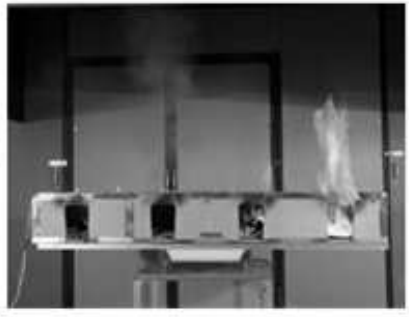

$570 \mathrm{~s}$

the fire test room, in compliance with ISO 9705 [9]. Figure 3 shows the exhaust hood (with a 3-m square area) and the model placed under it. The combustion gas from the ignited model and the entrainment air, which are collected by the exhaust hood, are mixed along the duct. Therefore, the mixture takes time to reach the sensors in the duct. This time lag in measurement is made up for by comparing with results of the standard propane burner. With the heat of combustion for the plywoods and cardboard from the cone calorimeter tests, the HRR can be obtained by measuring the mass loss rate, which in turn is measured by an electronic scale (QA60FEG-S of Sartorius) with a resolution of $1 \mathrm{~g} / \mathrm{s}$. To investigate flame propagation, $16 \mathrm{k}$-type thermocouples were installed in the model (Figure 2) to measure the temperature in the fire tests.

\section{Results of Model Test}

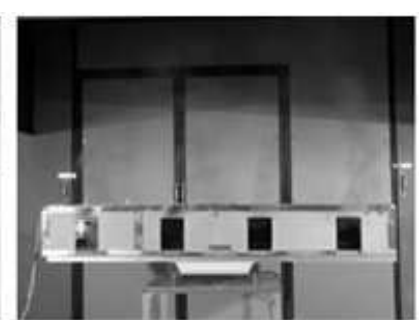

$200 \mathrm{~s}$

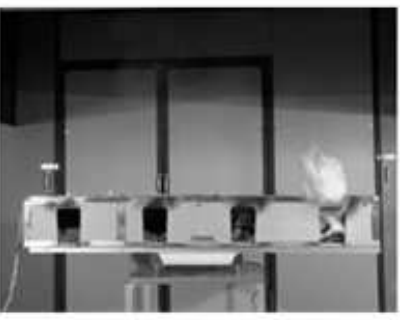

$780 \mathrm{~s}$

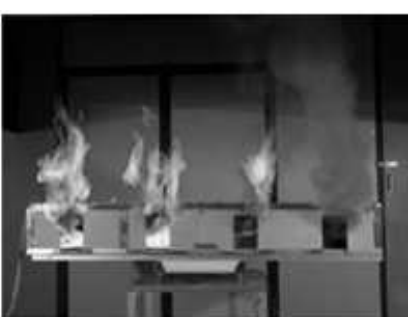

$300 \mathrm{~s}$

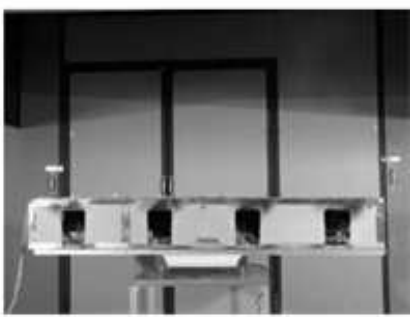

$910 \mathrm{~s}$

Figure 4. Fire development on the subway car for case B1.

Figure 4 presents photographs of the time course of fire propagation for case B1, in which 3-mm plywood was used as the interior material. Unless otherwise mentioned, time is represented in the reduced scale. The small seat near the fire source caught fire owing to radiative heat flux after about $100 \mathrm{~s}$. The fire started growing after $120 \mathrm{~s}$ and grew rapidly after $280 \mathrm{~s}$. The flames propagated beneath the ceiling of the model subway car, after which the floor was ignited because of the incident radiative heat flux. The difference in propagation time between the ceiling and floor at the same vertical position was about 70 to $90 \mathrm{~s}$, where the times were determined from both video clips and measured temperatures. Flames and smoke were subsequently emitted through the first three doors and the last door, respectively, after $300 \mathrm{~s}$. Table 3 shows the maximum HRR and the time to reach it for each case. For cases in which corrugated cardboard was used, the fire reached its peak after 123, 204, and $258 \mathrm{~s}$ for source locations 1 (case A1), 2 (case A2), and 3 (case A3), respectively. Interior materials burned more quickly near the fire source (case A1); hence, less time was required to reach the maximum HRR than in other cases (cases A2 and A3). Plywood materials showed the same location-dependent characteristics for the peak HRR. The fire spread fastest when the fire source was at the end wall. This demonstrates that the most vulnerable location during a subway car fire is at the end, because it is easily exposed to the fire source. For cases B3 and C3, in which a fire source of the same size was used, the fire burned only a portion of the interior materials around the fire source and died naturally. The fire did not grow; it was confined to the vicinity of the fire source because only the interior material of the ceiling was exposed directly to the source. Therefore, the nozzles for the water mist and sprinkler, which are installed to suppress a fire in a subway car, should ideally be installed toward the seats, sidewall, and end wall, rather than the center of the floor, to prevent flashover or fire propagation. Except for cases B3 
and C3, wherein the fire did not spread to the entire area, the peak HRR did not vary greatly with the location of fire source (Table 3). For case A, the ratio of the lowest peak HRR (case A1) to the highest peak HRR (case A2) was relatively small at 0.85 ; the ratio was 0.97 for case $\mathrm{B}$ and 0.91 for case C. Except for cases wherein the fire did not spread to the entire area, the difference in peak HRR among all interior materials was only $15 \%$. In short, the location of the fire in a subway car did not affect its size (HRR) greatly but considerably influenced the time to reach the peak HRR. Figures 5-7 show the HRRs for all cases. The difference in the time to reach the peak HRR increased according to the combustibility of interior materials (Table 3). Evaluation of combustibility by using the cone calorimeter revealed that among the interior materials, corrugated cardboard (case A) had the lowest combustibility, followed successively by 3-mm plywood (case B) and 5-mm Plywood (case C). Similar to the result of the specimen test, in the reduced-scale model, the time to reach the peak HRR was shortest in case A1, followed successively by cases $\mathrm{B} 1$ and $\mathrm{C} 1$. In the reduced-scale model test, the peak HRR was highest in case A, followed successively by cases C and B. This ordering was the reverse of that for the maximum HRR measured in the specimen test; presumably, case A had the highest HRR in the reduced-scale model test because of rapid spreading of the flame. Figure 8 shows the average temperature in the reduced-scale model. The filled gray plots represent the average temperature of the thermocouples on the ceiling, and the open black plots show the average temperature of all thermocouples installed in the model. Case $C$ (5-mm plywood) had a higher peak HRR than case B (3-mm plywood) because many interior materials burned simultaneously owing to the greater increase in temperature (Figure 8).

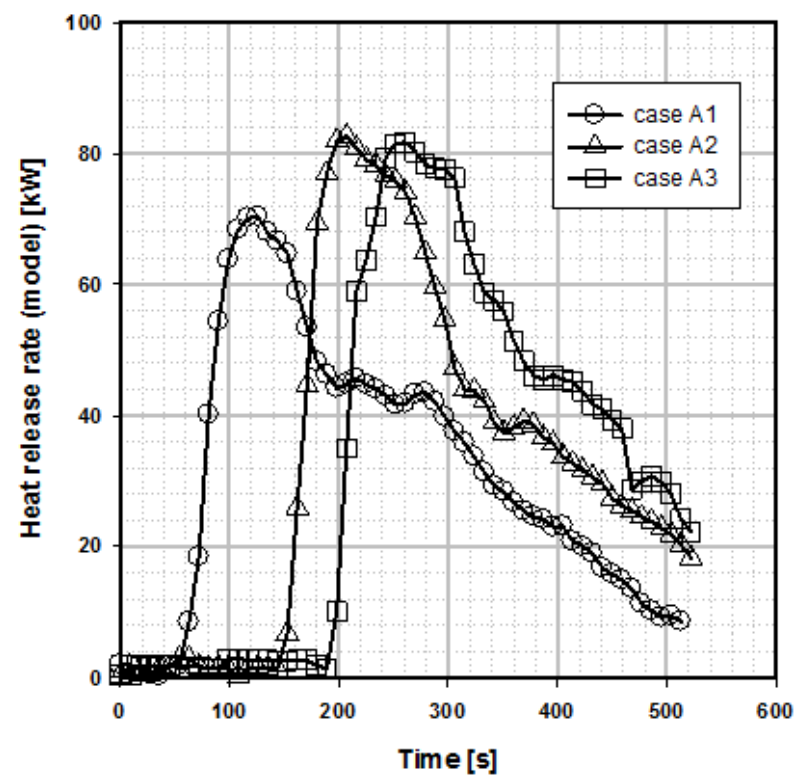

Figure 5. Heat release rates for case A.

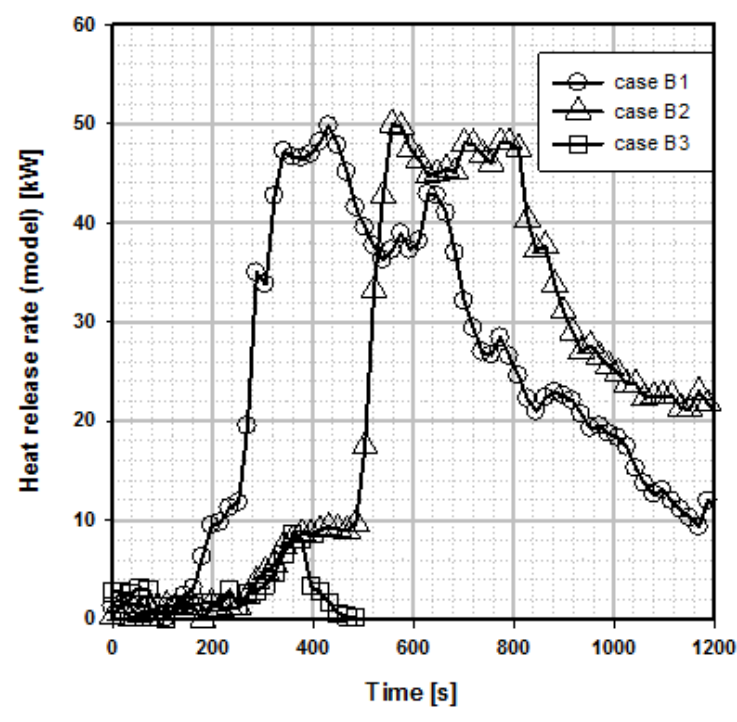

Figure 6. Heat release rates for case $B$.

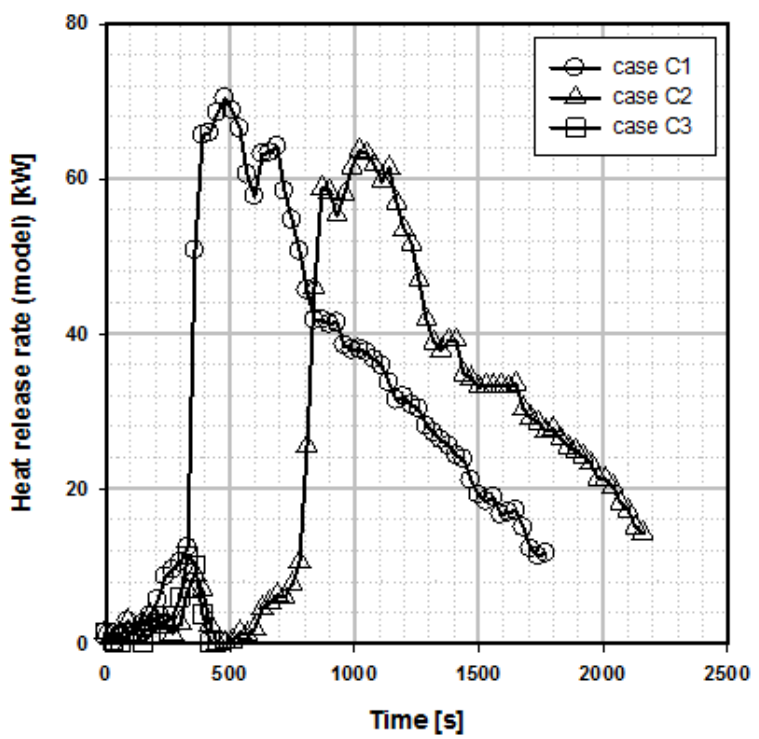

Figure 7. Heat release rates for case $C$.

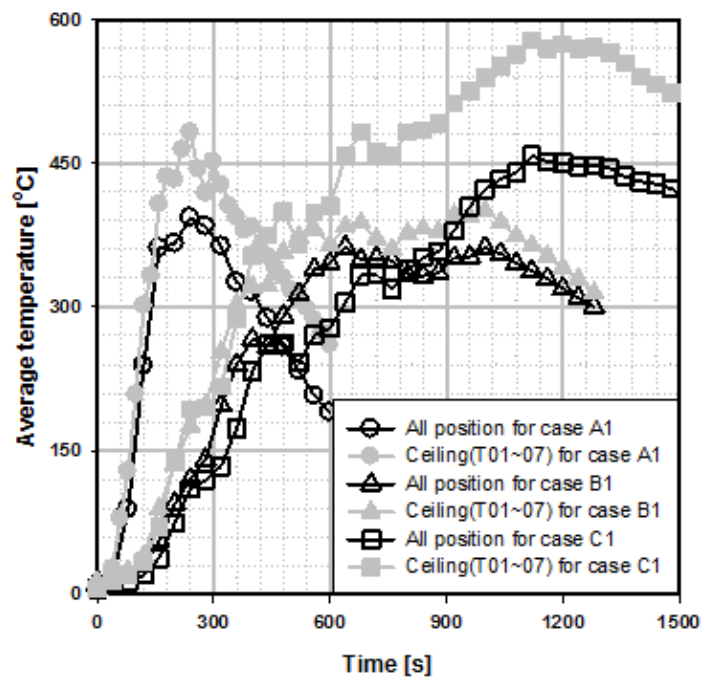

Figure 8. Average temperatures of all positions and ceiling. 


\section{Comparison with Full-Scale Test}

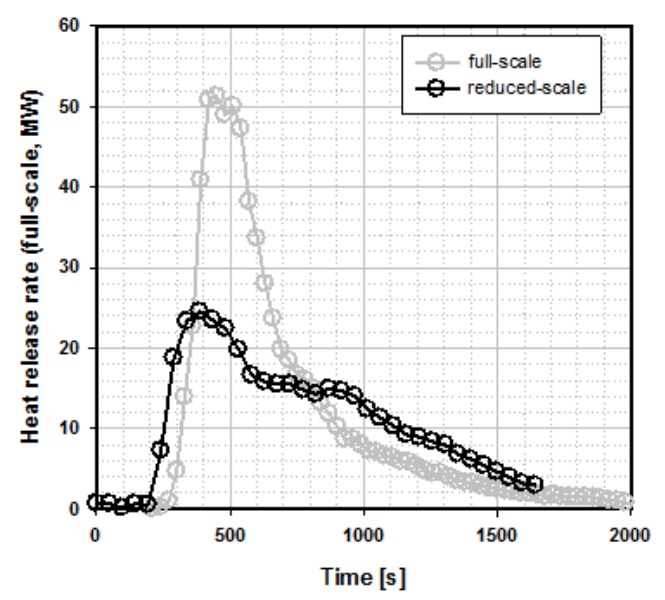

Figure 9. Heat release rate in the full-and reduced-scale tests.

In the full-scale test [5], the fire source was installed in the corner, in the same place as in cases $\mathrm{A} 1, \mathrm{~B} 1$, and $\mathrm{C} 1$ of this study. In each reduced-scale test, the time to reach the peak HRR converted using eq. (2) was 396, 1372, and 1614 s, respectively. The time to reach the peak HRR in the full-scale test was $430 \mathrm{~s}$, similar to the result of case A1. Hence, we selected case A1 as the reference. The HRRs of the reduced-scale and full-scale subway cars are compared in Figure 9. The peak HRR of the reduced-scale model was 24.7 MW, or $50 \%$ that of the full-scale model (52.5 MW). Although there are many reasons for the discrepancy between the reduced- and real-scale tests, the amount of interior materials used in the reduced-scale model is the likely reason for this large difference. The total fire load of the trailer car used in the full-scale test was 21.4 GJ [5]. The effective heat of combustion of a subway car with similar materials was $19.1 \mathrm{MJ} / \mathrm{kg}$ [11], and that of the reduced-scale model measured in the specimen test was $8.01 \mathrm{MJ} / \mathrm{kg}$. The total fire load of the real-scale subway car, converted to the reduced-scale by using eq. (3), was 45.5 MJ. This value was much larger than that of the actually used reduced-scale model (17.0 MJ). Therefore, the peak HRR of the reduced-scale model was measured to be smaller than that of the real-scale subway car. Measuring the peak HRR more accurately will require consideration of the similarity of the fire load when installing combustibles in the reduced-scale model fire test.

\section{Conclusions}

In sum, we used a 1/10-scale model of an actual subway car in a fire test and obtained the following results.

For a subway car, the peak HRR did not significantly differ according to the location of the fire, but the time of fire growth varied greatly.

The HRR changed rapidly in regions where the mass loss rate of the interior materials in the reduced-scale model trailer car changed rapidly. Measuring a more accurate peak HRR will require installing interior materials of the reduced-scale model by considering the similarity of the fire load.

The most vulnerable location during the fire was the end of the subway car, followed successively by the sidewall close to the seats and the center of the car.

When a subway car with many doors stops in an emergency at a nearby platform or tunnel, the open area becomes much wider than that for normal railcars. This is because the doors on one or both sides are open for passenger evacuation, and hence air (oxygen) is sufficient (the railcar is well ventilated). Therefore, the fire size of this type of railcar (having many open doors or windows) can be determined by the amount of interior materials (fire load) and their combustibility.

\section{Acknowledgement}

The author gratefully acknowledge the financial support from Disaster Safety Technology Development \& Infrastructure Construction Research Group and National Emergency Management Agency. (NEMA-Infra -2013- 103).

\section{References}

[1] Peacock R, Braun E, Fire tests of amtrak passenger rail vehicle interiors, National Bureau of Standards Technical Note 1193, 1984

[2] Fires in Transport Tunnels: Report on Full-Scale Tests. Edited by Studiensgesellschaft Stahlanwendung e. V., EUREKA-ProjectEU499: FIRETUN, Du“ sseldorf, Germany, 1995

[3] Peacock R, Bukowski R, Jones W, Reneke P, Babrauskas V, Brown J, Fire safety of passenger Trains, National Bureau of Standards Technical Note 1406, 1994

[4] Ingason H, Model scale railcar fire tests, Fire Safety J, 2007, 42(4): 271-282

[5] George H, Lee D -H and Park W -H, Full-scale experiments for heat release rate measurements of railcar fires, The 5th International Symposium on Tunnel Safety and Security, New York, USA, 14-16th March, 2012

[6] Lee D., Park W., Jung W, Yang S., Kim H., Hadjishophocleous G, Hwang J., Estimations of heat release rate curve in case of railcar fire, J Mech Sci Technol, 2013, 27(6):1665-1670

[7] Quintiere J G, Scaling Application in Fire Research, Fire Safety J 15(1): 3-29, 1989

[8] ISO $5660-1$, Reaction to fire tests - Heat release, smoke production and mass loss rate - Part 1 : Heat release rate(cone calorimeter method, 2002

[9] ISO 9705, Fire tests-Full-scale room test for surface products, 1996.

[10] Huggett C, Estimation of rate of heat release by means of oxygen consumption measurements, Fire Mater, 1980, 4(2): $61-65$

[11] Korea Land, Transport and Maritime Affairs, Technology development of safety evolution and accident prevention for railway fire, 2010. 